\title{
Domestic and Foreign Tourists Arrivals in Goa: Growth Examiation
}

\author{
Sukhaji G. Naik
}

\begin{abstract}
An attempt is made in this paper, to examine growth trend of domestic and foreign tourists arrivals, month wise tourist arrivals, nation wise foreign tourists arrivals, foreign tourists arrivals, foreign tourists arrive by flights and the growth of hotels, no. of rooms and no. of beds. The required data is collected from the reports of tourists statistics, Department of tourism, Govt. of Goa. Further, the data collected for 30 years is divided into two sub periods namely sub period I (1988-89 to 2002-03) and sub period II (2003-04 to 2017-18) and a comparative growth of domestic and foreign tourists arrivals is studied. A chain index statistical tool is employed to compute yearwise growth trend. The study reveals that the foreign tourists recorded more fluctuation in the growth as compared to the growth trend of domestic tourists. Country wise arrivals of tourists shows that Russia has registered the highest tourists arrivals followed by UK and Ukrain. The yearwise growth of tourists arrivals shows a marginal variation during the study period.
\end{abstract}

Keywords : Domestic and foreign tourist, Inbound tourism, Outbound tourism, Ethnic tourism.

\section{BACKGROUND}

$\mathrm{T}_{\mathrm{h}}$ he world tourism organization defines tourists as people travelling to and staying in places outside their usual environment for not more than one consecutive year for leisure, business and other purposes. Tourism is travel for recreation, leisure, religious, family or business purposes. Tourism can be domestic or international. Its importance was recognized in the Manila Declaration on world Tourism of 1980 as "an activity essential to the life of nations because of its direct effects on Social, Cultural, educational and economic sectors of national societies and on their international relations" Tourism involves mainly three important components: Accessibility, accommodation, and attraction. In 1994 , the United Nations identified three forms of tourism in its recommendations:

Domestic Tourism involving residents of the given country travelling only within this country, inbound tourism involving non-residents travelling in the given country and outbound tourism

Revised Manuscript Received on September 25, 2019

* Correspondence Author

Dr. Sukhaji G. Naik *, Associate Professor, Vice Principal and HOD Dept. of Commerce, Vidya Prabodhini College of Commerce, Education, Computer and Management, Parvari Goa. involving residents travelling in another country.

\section{TYPES OF TOURISM}

\section{* Recreational tourism:}

Recreational tourism is what most people have in mind when tourism is mentioned such people mainly save for change \& rest where mass \& popular package tours seek mainly seen sea sand \& fresh air or sporting activities of various kinds are there.

* Cultural tourism:

Cultural tourism is to experience new cultural activities i.e. folklore music etc. culture refers to a set of beliefs, values, attitudes, habits and forms of behavior that are shared by a society and are transmitted from generation to generation. Culture is felt by individuals in different ways, culture affects the daily life patterns of individuals in society, concept of time varies from culture to culture, the social groups to which that individual belongs and the society as a whole will enable the marketer to sell a travel product. The culture of different countries can vary greatly to attract people from a particular country it is important to know cultural difference.

\section{* Historical tourism:}

It is fully related to Heritage locations museums, churches, temples \& antique treasures which recall the past.

*thnic tourism:

Ethnic tourism involves contacts with unusual or quaint customs in remote areas visiting the family's country of ringing \& relatives \& friends. Visiting friends and relatives (VFR) is an important motive behind much of the inbound tourism in India.

* Environmental tourism:

There are different classes of people who would like to be in natural environment \& visit nature specially the higher groups in particular are interested in visiting remote environments.

\section{* Adventure tourism:}

Adventure tourism is related to promote the people who are interested in enjoying adventure activities, adventure tourism is glared to promote mountaineering trekking \& adventure activities. 


\section{Domestic and Foreign Tourists Arrivals in Goa: Growth Examiation}

\section{* Medical tourism:}

Medical tourism benefits tourists from worldwide advancements of health care and the globalization of the market place. Here patients going to different country for either urgent or elective medical procedures are benefited.

\section{HIGHLIGHTS OF INDIAN TOURISM}

- Tourist arrivals in India increased to 8,91,000 in November from 7,54,000 in October, 2016. It averaged 4,26,846.43 from 2000 until 2016, reaching an all-time high of 9,13,000 in December, 2015 and a record low of 1,29,286 in May, 2001.

- The number of Foreign Tourist Arrivals (FTAs) in India during 2017 increased to 10.04 million as compared to 8.80 million in 2016. The growth rate in FTAs during 2017 over 2016 was $14.0 \%$ as compared to $9.7 \%$ during 2016 over 2015.

- The share of India in international tourist arrivals in 2017 was $1.2 \%$. India accounted for $4.8 \%$ of international tourist arrivals in Asia Pacific Region in 2017 with rank of 7th.

- About $79.6 \%$ of the FTAs entered India through air routes followed by $19.7 \%$ by land routes and $0.7 \%$ by sea routes. Delhi and Mumbai airports accounted for about $44.1 \%$ of the total FTAs in India. The top 15 source markets for FTAs in India in 2017 were Bangladesh followed by United States, United Kingdom, Canada, Australia, Malaysia, Sri Lanka, Russia Federation, Germany, France, China, Japan, Singapore, Nepal and Afghanistan. The top 15 countries accounted for about $75.35 \%$ of total FTAs in India in 2017.

- Tourism continues to play an important role as a foreign exchange earner for the country. In 2017, foreign exchange earnings (FEE) from tourism were US $\$ 27.31$ billion as compared to US\$22.92 billion in 2016, registering a growth of $19.1 \%$

- Number of domestic tourist visits in India during 2017 was 1652 million (Provisional) as compared to 1615 million in 2016 , with a growth rate $2.3 \%$.

- Number of Indian national departures from India during 2017 was 23.94 million as compared to 21.87 million in 2016, registering a growth rate of $9.5 \%$.

\section{TOURISM IN GOA}

Goa was liberated from the Portuguese regime yoke on 19th December, 1961 and remained Union territory along with Daman and Diu for several years. Goa was elevated to the status of 25th state in the Indian Union on 30th May, 1987. It has a geographical area of 3702 sq kms and a population 14.57 lakhs (2011 census).
The state is divided into two districts and twelve talukas. The state has the highest per capita income in the country and the second lowest with respect to poverty rate. Tourism, agriculture, Industry, mining, construction, banking, trade and fishery are the main economic activities of Goan economy. Goa with its unique natural beauty, has emerged as one of the best and the most attractive tourist destination in the world.

Goa is known as the "Rome of the East" having an area of lush green mountains, blue waters and white sands, winding rivers and picturesque villages with local flora and fauna Goa is thus famous for tourism. Tourism is important because it helps to maintain goa's economy and also great contributors to exchange. It is a small state, with $140 \mathrm{~km}$ from North to South and $65 \mathrm{Km}$ from East to West. Goa beaches have become the major attraction for the tourists such as Agonda, Calangute, Candolim, Dona Paula etc. Besides this, there are also churches like Basilica of Bom Jesus, St. Francis of Assisi, St. Augustine and others. The state is famous for unending carnivals; Christmas and the sunburn festival are the centre of attraction of tourists. Goa receives largest number of tourists from Germany, Finland, UK, France, USA etc. The domestic tourists come from all over India as it is very popular tourists' destination. Goa caters to the tastes of various tourists through the various types of tourism such as Beach Tourism, Adventure tourism, Wildlife Tourism, Pilgrimage Tourism and Cultural Tourism.

\section{SOCIO ECONOMIC IMPORTANCE OF TOURISM}

During past decades, tourism has become an effective venture. Tourist arrival rate is growing year by year. With advancement in supporting tools and technologies e.g. computerized reservation system, online payment, fast transportation, infrastructures etc tourism started to affect all the aspects of destination including social, cultural, economical etc. some of the obvious advantages of tourism are foreign exchange income, sales of local products employment etc .

Economical effects of tourism are directly observable. Tourism generates different types of income for a community: business income, wage earnings, share earnings, rates and levies. Direct spending by visitors has a positive impact on business profitability and employment growth. The money that is then circulated and re-spent in the economy is often referred to as indirect spending or the multiplier effect. Because much of a region's tourism patronage comes from metropolitan centers, it is an effective way to redistribute wealth from 
urban to rural areas. The expectations and needs of visitors can often lead to the creation of new businesses and commercial activities. This builds a more diverse economic base and reduces reliance on one or two traditional industries, which is often the case in rural communities. A thriving tourism industry supports growth in other sectors, such as transport, construction, agriculture and retailing. As tourism increases, there are more opportunities for small business to develop. The main positive economic impacts of tourism relate to foreign exchange earnings, contributions to government revenues, generation of employment and business opportunities. Tourism expenditures, the export and import of related goods and services generate income to the host economy. Tourism can induce the local government to improve the infrastructure by creating better water and sewage systems, roads, electricity, telephone and public transport networks. All this can improve the quality of life for residents as well as facilitate tourism. Tourism can be a significant or even an essential part of the local economy. Because environment is a basic component of the tourism industry's assets, tourism revenues are often used to measure the economic value of protected areas. There are other local revenues that are not easily quantified, as not all tourist expenditures are formally registered in the macro-economic statistics. Part of the tourism income comes from informal employment, such as street vendors and informal guides. The positive side of informal or unreported employment is that the money is returned to the local economy and has a great multiplier effect as it is spent over and over again

\section{OBJECTIVES OF THE STUDY}

The following objectives are set for the study:

1. To study the growth trends of domestic and foreign tourist's arrivals in the state of Goa.

2. To analyse month-wise tourists arrivals during 2017.

3. To analyse a Nation- wise foreign tourists' arrivals.

4. To know the foreign tourists' arrival by flights.

5. To study growth of total number of Hotels, number of rooms and the total number of Beds.

\section{DATA AND METHODOLOGY}

The undertaken study is based on secondary data. The necessary data is collected from the tourist statistics, Department of tourism, Govt. of Goa, Goa Economic survey: 2017-18 and from the different reference books on tourism. The required data pertaining to domestic and foreign tourist's arrivals for the period of 30 Years from 1988-89 to 2017-18 are collected. Further the 30 years data of domestic and foreign tourists' arrivals are divided into two sub periods viz, sub-period I (1988-89 to 2002-03) and sub - period II (2003-04 to 2017-18) and a comparative growth of domestic and foreign tourists' arrivals is studied. Over and above, the Nation-Wise domestic and foreign tourist arrival is studied during 2018. The study has also made an attempt to understand foreign tourist's arrivals by flights for the period from 2004-05 to 2017-18. Notwithstanding, attempt is also made to study the growth of total number of Hotels, number of rooms and number of beds as on 31/03/2019. A chain index statistical tool is employed to compute an year-wise growth trend of domestic and foreign tourist arrivals during 1988-89 to 2017-18. A simple percentages and averages are used to analyse the collected data.

\section{ANALYSIS AND DISCUSSION}

Table 1: Growth analysis of Domestic and Foreign Tourists Arrivals in Goa During first sub period (1989 to 2003 (15 Years: Period I))

(Figures in Actuals)

\begin{tabular}{|c|c|c|c|c|c|r|}
\hline Year & Domestic & $\begin{array}{c}\text { Chain } \\
\text { Index }\end{array}$ & Foreign & $\begin{array}{c}\text { Chain } \\
\text { Index }\end{array}$ & Total & $\begin{array}{c}\text { Chain } \\
\text { Index }\end{array}$ \\
\hline 1989 & 771013 & 100 & 91430 & 100 & 862443 & 100 \\
\hline 1990 & 776993 & 100.78 & 104330 & 114.11 & 881323 & 102.19 \\
\hline 1991 & 756786 & 97.40 & 78281 & 75.03 & 835067 & 94.75 \\
\hline 1992 & 774568 & 102.35 & 121442 & 155.14 & 896010 & 107.30 \\
\hline 1993 & 798576 & 103.10 & 170658 & 140.53 & 969234 & 108.17 \\
\hline 1994 & 849404 & 106.36 & 210191 & 123.17 & 1059595 & 109.32 \\
\hline 1995 & 878487 & 103.42 & 229218 & 109.05 & 1107705 & 104.54 \\
\hline 1996 & 888914 & 101.19 & 237216 & 103.49 & 1126130 & 101.66 \\
\hline 1997 & 928925 & 104.50 & 261673 & 110.31 & 1190598 & 105.72 \\
\hline 1998 & 953212 & 102.61 & 275047 & 105.11 & 1228259 & 103.16 \\
\hline 1999 & 960114 & 100.72 & 284298 & 103.36 & 1244412 & $1043^{3} 32$ \\
\hline
\end{tabular}


Domestic and Foreign Tourists Arrivals in Goa: Growth Examiation

\begin{tabular}{|c|c|c|c|c|c|c|}
2000 & 976804 & 101.74 & 291709 & 102.61 & 1268513 & 101.94 \\
\hline 2001 & 1120242 & 114.68 & 260071 & 89.15 & 1380313 & 108.81 \\
\hline 2002 & 1325296 & 118.30 & 271645 & 104.45 & 1596941 & 115.69 \\
\hline 2003 & 1725140 & 130.17 & 314357 & 115.72 & 2039497 & 127.71 \\
\hline TOTAL & $\mathbf{1 4 4 8 4 4 7 4}$ & $\mathbf{1 5 8 7 . 3 4}$ & $\mathbf{3 2 0 1 5 6 6}$ & $\mathbf{1 6 5 1 . 2 2 9}$ & $\mathbf{1 7 6 8 6 0 4 0}$ & $\mathbf{1 5 9 2 . 3}$ \\
\hline MEAN & $\mathbf{9 6 5 6 3 1 . 6}$ & $\mathbf{1 0 5 . 8 2}$ & $\mathbf{2 1 3 4 3 7 . 7}$ & $\mathbf{1 1 0 . 0 8 2}$ & $\mathbf{1 1 7 9 0 6 9 . 3}$ & $\mathbf{1 0 6 . 1 5}$ \\
\hline
\end{tabular}

Source: Tourist Statistics 2012, Department of tourism, Govt. of Goa, Panaji.

Tourism occupies an important place in the economy of Goa and the tourists' arrivals is certainly promoting economic growth in terms of different economic activities in the state. In this context, the growth trend of domestic and foreign tourists is computed with the help of statistical index and the computed values are presented in Table 1 . The total number of domestic tourists are increased from 771013 in the year 1989 to 1725140 during 2003. As far as the foreign tourists are concerned, the total number of foreign tourists' arrivals have gone up from 91430 during 1989 to 314354 during 2003. The computed chain Index values reveal that during all the 15 years, year wise growth trend is observed to be more or less the same with a marginal variation. However, it is interesting to note that during 2001 to 2003, the growth of tourists' arrivals is upward trend. The domestic tourist's arrival registered on an average $5.82 \%$ growth during the study period. The calculated chain index values of foreign tourists' arrivals show that the growth trends are noticed to be a fluctuating trend and the year-wise values show a lot of variation in the growth trend of tourists. On an average, during the whole period, the foreign tourists have registered, the growth of $10.08 \%$. The foreign tourists have recorded more fluctuation as compared to the growth trend of domestic tourists. It means, domestic tourists visit throughout the year and the foreign tourists visit Goa during a particular season. The overall tourists including domestic as well as foreign, have registered on an average growth of $6.15 \%$ during the study period. The overall analysis indicates that there is no significant year-wise growth of both domestic and foreign tourists during the study period. Between domestic and foreign tourists, domestic tourists have made a good growth as compared to the growth record of foreign tourists.

Table 2: Growth analysis of Domestic and Foreign Tourists Arrivals in Goa During second sub period 2004 to 2018 (15 Years: Period II)

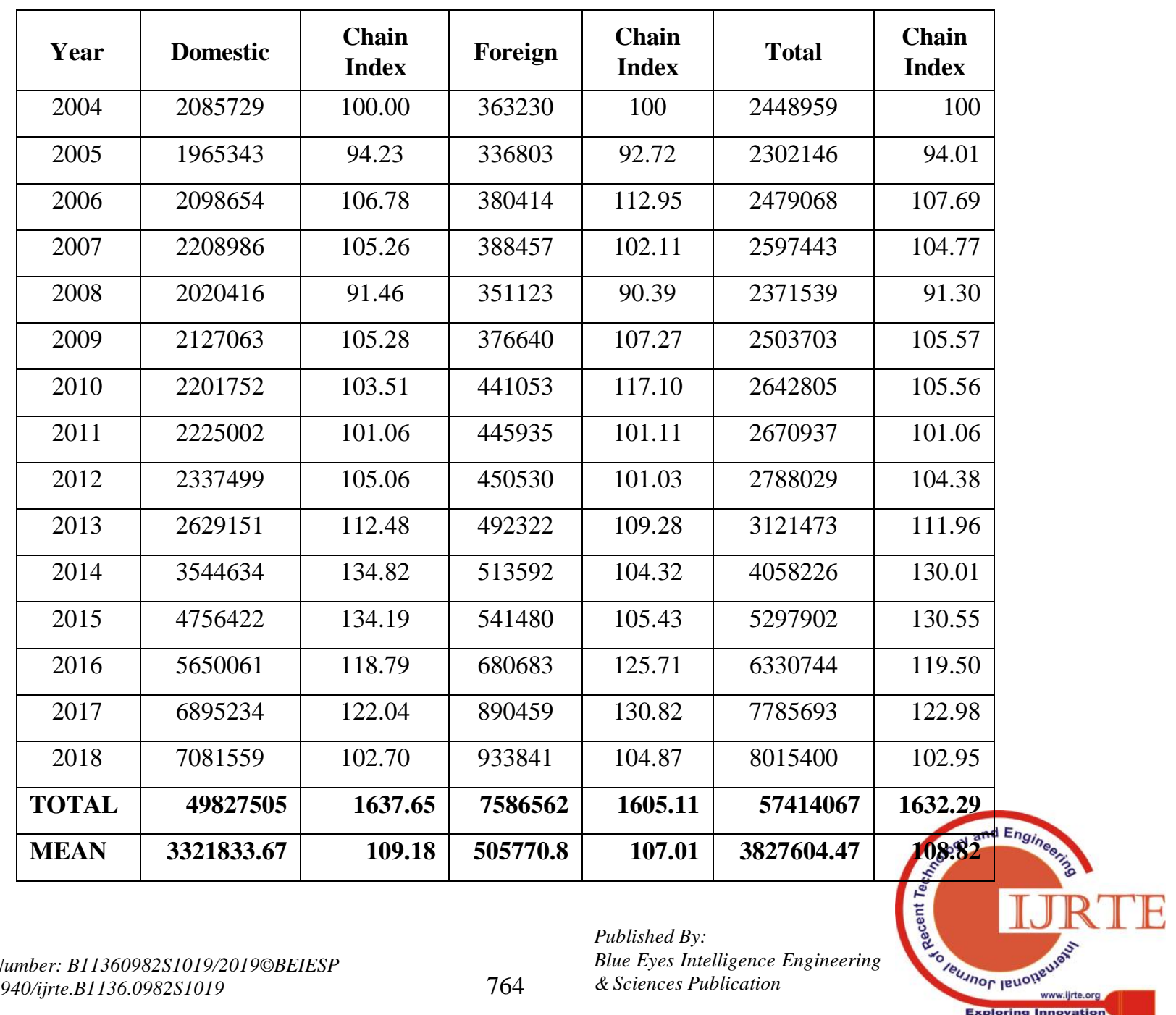


Source: Tourist Statistics 2012, Department of tourism, Govt. of Goa, Panaji.

The growth trend of domestic and foreign tourists is computed with the help of statistical index and the computed values are presented in Table 2 . The total number of domestic tourists have increased from 2085729 in the year 2004 to 7081559 during 2018. As far as the foreign tourists are concerned, the total number of foreign tourist's arrivals have gone up from 363230 during 2004 to 933841 during 2018. The computed chain Index values reveal that during all the 15 years, year wise growth trend is observed to be more or less the same with a marginal variation. However, it is interesting to note that during 2013 to 2018 , the growth of tourist's arrivals is upward trend. The domestic tourist's arrival registered on an average $9.18 \%$ growth during the study period. The calculated chain index values of foreign tourist's arrivals show that the growth trends are noticed to be a fluctuating trend and the year-wise values show a lot of variation in the growth trend of tourists. On an average, during the whole period, the foreign tourists have registered, the growth of $7.1 \%$.The foreign tourists have recorded upward trend for two years viz. 2016 and 2017 . This could be due to efforts taken by Department of Tourism, Government of Goa in promoting Goa Tourism in foreign countries through various exhibitions and promotional events. The overall tourists including domestic as well as foreign, have registered on an average growth of $8.82 \%$ during the study period. The overall analysis indicates that there is no significant year-wise growth of both domestic and foreign tourists during the study period. Between domestic and foreign tourists, domestic tourists have made a good growth as compared to the growth record of foreign tourists.

Table 3: Month wise Domestic and Foreign Tourists arrivals during 2017

\begin{tabular}{|l|r|r|r|r|r|r|}
\hline \multicolumn{1}{|c|}{ Month } & Domestic & Chain Index & \multicolumn{1}{c|}{ Foreign } & Chain Index & \multicolumn{1}{c|}{ Total } & Chain Index \\
\hline January & 306059 & 100 & 116215 & 100 & 422274 & 100 \\
\hline February & 242098 & 79.10 & 98163 & 84.47 & 340261 & 80.58 \\
\hline March & 242296 & 100.08 & 91709 & 93.43 & 334005 & 98.16 \\
\hline April & 478069 & 197.31 & 67961 & 74.11 & 546030 & 163.48 \\
\hline May & 730441 & 152.79 & 21192 & 31.18 & 751633 & 137.65 \\
\hline June & 502230 & 68.76 & 16218 & 76.53 & 518448 & 68.98 \\
\hline July & 439663 & 87.54 & 9613 & 59.27 & 449276 & 86.66 \\
\hline August & 448750 & 102.07 & 13762 & 143.16 & 462512 & 102.95 \\
\hline September & 467518 & 104.18 & 20568 & 149.46 & 488086 & 105.53 \\
\hline October & 844742 & 180.69 & 80545 & 391.60 & 925287 & 189.57 \\
\hline November & 1011818 & 119.78 & 158922 & 197.31 & 1170740 & 126.53 \\
\hline December & 1184250 & 117.04 & 195591 & 123.07 & 1379841 & 117.86 \\
\hline TOTAL & 6897934 & 1409.33625 & 890459 & 1523.58281 & 7788393 & 1377.94533 \\
\hline MEAN & 574827.8 & 117.444687 & 74204.92 & 126.965235 & 649032.8 & 114.828778 \\
\hline
\end{tabular}

Source: Tourists statistics, Department of Tourism, Govt. of Goa Panaji

The month-wise domestic and foreign tourists' arrivals and computed Year-wise chain index values are depicted in table 3. It can be witnessed from the table that the calculated chain index reveal that, in case of domestic tourists, the April, May, October, November and December months have registered the significant growth in the domestic tourists arrivals indicating the domestic tourists preference of visiting Goa during those months . It means, the domestic tourists have preferred to visit during summer and winter seasons. The computed values during other months are observed to have recorded a fluctuating trend showing less preference of tourists during those months.
The computed values of chain index of foreign tourists show that the months viz, August, September, November and December have made an impressive growth in the arrivals of foreign tourists. The analysis further indicates that the foreign tourists prefer to visit Goa more during rainy and winter seasons. The foreign tourists have registered on an average $126 \%$ during the whole year and the domestic tourists have recorded on an average $117 \%$ growth The foreign tourists have made good growth as compared to the average growth of domestic tourists. The total tourists arrivals have recorded $114 \%$ growth during the whole year. 


\section{Domestic and Foreign Tourists Arrivals in Goa: Growth Examiation}

Table 4: Country - wise Tourists Arrivals analysis during 2018

(Figures in Actuals)

\begin{tabular}{|c|c|c|c|}
\hline No. & Countries & Tourist Arrived & Percentage \\
\hline 1 & U.K. & 294569 & 31.54 \\
\hline 2 & Russia & 333565 & 35.72 \\
\hline 3 & Germany & 19427 & 2.080 \\
\hline 4 & Ukraine & 46826 & 5.01 \\
\hline 5 & Finland & 10685 & 1.14 \\
\hline 6 & France & 8645 & 0.93 \\
\hline 7 & Switzerland & 5090 & 0.55 \\
\hline 8 & Sweden & 6127 & 0.66 \\
\hline 9 & U.S.A. & 154 & 0.02 \\
\hline 10 & Australia & 2874 & 0.31 \\
\hline 11 & South Africa & 21744 & 2.33 \\
\hline 12 & Brazil & 9124 & 0.98 \\
\hline 13 & Italy & 641 & 0.07 \\
\hline 14 & Canada & 4151 & 0.44 \\
\hline 15 & Japan & 25674 & 2.75 \\
\hline 16 & Denmark & 8473 & 0.91 \\
\hline 17 & Austria & 643 & 0.07 \\
\hline 18 & Holland & 7055 & 0.76 \\
\hline 19 & Portugal & 2537 & 0.27 \\
\hline 20 & Ireland & 1163 & 0.12 \\
\hline 21 & Belgium & 959 & 0.10 \\
\hline 22 & Norway & 1584 & 0.17 \\
\hline 23 & Iran & 469 & 0.05 \\
\hline 24 & U.A.E. & 1034 & 0.11 \\
\hline 25 & New Zealand & 361 & 0.04 \\
\hline 26 & Greece & 210 & 0.02 \\
\hline 27 & Lithuania & 324 & 0.03 \\
\hline 28 & Czech & 218 & 0.02 \\
\hline 29 & Others & 119515 & 12.80 \\
\hline \multicolumn{2}{|r|}{ TOTAL } & 933841 & 100.00 \\
\hline
\end{tabular}

Source: Tourist statistics, Department of Tourism, Govt. of Goa, Panaji - Goa.

Goa state has been recognized as an international tourist destination because of its beautiful beaches, excellent infrastructure facilities, safety and security measures, good hospitality, quality services, well connected transportation network, efficient service providers and soon. The country-wise tourists arrivals during 2018 is presented in the table 4. It is learnt from the table that of the total major countries, Russia is observed to have recorded the highest tourist arrival i.e $35.72 \%$ of the total tourist visited to Goa, followed by United Kingdom recording the second highest tourists arrivals i.e $31.54 \%$ of the total tourists arrivals . The third highest is observed to be the Ukrain ie $5 \%$ of the total tourists visited to Goa. Further, Australia, Japan and Germany have registered 2\% respectively of the total tourists arrivals. The remaining countries have registered a negligible percentage i.e less than $1 \%$ of the total tourists arrivals to Goa . There is still scope to attract tourists sizably from other countries. 
Table 5:Analysis of Number of Flights and Tourists' arrivals during 2004-05 to 2017-18

\begin{tabular}{|c|c|c|c|c|}
\hline Year & No. of Flights & Chain Index & Tourists Arrival & Chain Index \\
\hline $2004-2005$ & 690 & 100.00 & 158993 & 100.00 \\
\hline $2005-2006$ & 719 & 104.20 & 180310 & 113.41 \\
\hline 2006-2007 & 720 & 100.14 & 169836 & 94.19 \\
\hline 2007-2008 & 710 & 98.61 & 175951 & 103.60 \\
\hline $2008-2009$ & 615 & 86.62 & 145428 & 82.65 \\
\hline $2009-2010$ & 626 & 101.79 & 137790 & 94.75 \\
\hline 2010-2011 & 900 & 143.77 & 171367 & 124.37 \\
\hline $2011-2012$ & 910 & 101.11 & 169006 & 98.62 \\
\hline $2012-2013$ & 996 & 109.45 & 215304 & 127.39 \\
\hline $2013-2014$ & 1128 & 113.25 & 261452 & 121.43 \\
\hline $2014-2015$ & 895 & 79.34 & 161316 & 61.70 \\
\hline 2015-2016 & 798 & 89.16 & 158779 & 98.43 \\
\hline $2016-2017$ & 988 & 123.81 & 232679 & 146.54 \\
\hline $2017-2018$ & 981 & 99.29 & 247365 & 106.31 \\
\hline TOTAL & 11676 & 1450.55 & 2585576 & 1473.40 \\
\hline MEAN & 834 & 103.61 & 184684 & 105.24 \\
\hline
\end{tabular}

Source: Tourist statistics, Department of Tourism, Govt. of Goa, Panaji - Goa.

The number of flights and the tourists arrived to Goa during 2004-05 to 2017-18 are presented in table 5. It can be observed from the table that the total number of flight have been increased from 690 during 2004-05 to 981 during 2017-18, registering $42 \%$ growth during the study period. In the year 2013-14, the number of flights have registered the highest i.e 1128 followed by $2012-13$, the second highest, i.e 996, 2016-17, the third highest and during 2017-18, the flights have registered the fourth highest during the study period. . The calculated year-wise index values show a fluctuating trend with a marginal variation. Further, the number of flights have registered an impressive growth during 2010-11 and during 2016-17. On an average growth of flights arrived is $103.61 \%$ during the study period.

The tourist arrival for the corresponding period shows that the total number of tourists have gone up from 158993 during 2004-05 to 247365 during 2017-18. The calculated chain index values show the existence of year-wise variation in the total arrivals during the study period. In the year 2016-17, it is observed that the tourists have registered an annual growth of $105.25 \%$.

Table 6: Analysis of Total No. of Hotels, No. of Rooms and No. of Beds on 31/03/2019

(Figures in actuals)

\begin{tabular}{|l|c|r|r|r|r|r|}
\hline Category & No. of Hotels & \multicolumn{1}{|c}{$\%$} & No. of Rooms & \multicolumn{1}{c|}{ No. of Beds } & $\%$ \\
\hline A & 84 & 2.19 & 9034 & 20.95 & 15189 & 20.62 \\
\hline B & 252 & 6.57 & 10156 & 23.54 & 17467 & 23.72 \\
\hline C & 715 & $18 . .64$ & 11450 & 26.53 & 20495 & 27.82 \\
\hline D & 2784 & 72.60 & 12508 & 28.98 & 20516 & 27.84 \\
\hline TOTAL & 3835 & 100.00 & 43148 & 100.00 & 73667 & 100.00 \\
\hline
\end{tabular}

Source: Tourist statistics 2012, Department of Tourism, Govt. of Goa, Panaji - Goa.

Accommodation is a significant component of tourism and to attract tourists, adequate, comfortable and convenient accommodation and other related services assume paramount importance in promoting tourism. The total number of hotels, number of rooms and number of beds are displayed in table 6. From the table, it can be witnessed that out of the total 3835 hotels $72.6 \%$ represent category D hotels, followed by $18.64 \%$ category C hotels, $6.57 \%$ 
category B and mere $2.19 \%$ category A hotel. The category D is observed to have represented a Lions share in the total hotels. The availability of number of rooms analysis reveals that again the category $\mathrm{D}$ has accounted the highest in the total rooms followed by category $\mathrm{C}, \mathrm{B}$ and $\mathrm{A}$. It is further noticed that all the category of hotels have almost equal representation in the hotel rooms. The total number of beds are 73647 of which category D and C represent $27.84 \%$ and $27.82 \%$ respectively and category $\mathrm{B}$ and A represent $23.72 \%$ and $20.62 \%$ respectively. Incase of the total number of beds also there is no significant variation across the different category of hotels.

\section{CONCLUSION}

The undertaken study has introspected the growth of tourists' arrivals to Goa with regard to domestic and foreign tourists' for a period of 30 years, nation wise tourists' arrivals, month wise tourists' arrivals, arrivals by flight and the total number of hotels, rooms and the total number of beds. The analysis and discussion broadly reveals that the year wise growth trend of domestic and foreign tourists is observed to be almost the same with a marginal variation. However, during 2001 to 2003 growth was observed to be an upward trend. The foreign tourists have recorded more fluctuation as compared to the growth trend of domestic tourists. Domestic tourists visit throughout the year and foreign tourists visit during a particular season. No significant year wise growth during the study period. Month wise tourists analysis reveals that domestic tourists registered significant growth during April, May, October, and December. Whereas foreign tourists' registered good growth during August, September, November, and December. Country wise tourists' arrivals showed that Russia has registered the highest tourist arrivals, followed by U.K and Ukrain. Majority of the countries registered less than one percent of the total tourist arrivals. The number of flights registered on an average $42 \%$ growth during the study period. The hotel analysis showed that more than $72 \%$ of the total number of hotels represented category $\mathrm{D}$ hotels and all the category hotels registered almost equal representation in the total rooms. In case of the total number of beds, there is no significant variation across different category of hotels.

\section{REFERENCES}

1. Datt, Gaurav and Mahajan, Ashwani (2016), Datt and sundharams Indian economy, S. Chand and company Pvt. Ltd, New Delhi

2. Gupta, S C (2014), Fundamentals of statistics, Himalaya publishing house, Mumbai.

3. Kothari, C R and Garg, Gaurav (2014), Research methodology: Methods and techniques, New Age international (P) Ltd. Publishers, New Delhi

4. Bhatt, Harish (2006), Hospitality and tourism management, Crescent Publishing Corporation, New Delhi

5. Bhatia, A K (2009), Tourism development: Principles and Practice, Sterling Publishers Private Ltd, New Delhi

6. Economy Survey Report 2017-18

7. http://www.uou.ac.in/sites/default/files/slm/BTTM-503.pdf

8. Tourist statistics (2002), Department of Tourism, Govt. of Goa, Panaji Goa. 